\title{
Material Property Evaluation of Different Commercially-Available UHPC-Class Materials
}

Igor De la Varga ${ }^{\text {a }}$, Zachary Haber ${ }^{\text {b }}$, Jiqiu Yuan ${ }^{\text {b }}$, Benjamin A. Graybeal ${ }^{\text {c }}$

(a) SES Group \& Associates, USA

(b) Professional Service Industries, Inc., USA

(c) Federal Highway Administration, USA

\begin{abstract}
Ultra-high performance concrete (UHPC) is emerging as a viable solution for a wide variety of engineered infrastructure applications, including structural elements, retrofits, and field-cast connections. The U.S. Federal Highway Administration has a strong interest in investigating the properties of UHPCs for applications in the highway infrastructure, particularly in regard to the use of UHPC as a field-cast grout to complete the connections between prefabricated bridge elements (PBEs). The structural concrete research group at the federal Highway Administration Turner-Fairbank Highway Research Center (FHWA-TFHRC) is currently conducting a study on the performance of five different, commercially-available UHPC-class materials. This paper focuses on the materials-level behavior of these different UHPC products; emphasis is placed on properties that are critical to PBE connection applications. These properties include flowability, setting time, strength gain, dimensional stability, and bond to precast concrete. Results indicate that these materials behave similarly with respect to some performance measures such as compressive and tensile strength, but vary with respect to others such as dimensional stability and bond to precast concrete.
\end{abstract}

Keywords: UHPC, Fresh and Mechanical Properties, Dimensional Stability, Bond Strength

\section{Introduction and Objective}

Ultra-high performance concrete (UHPC) is gaining interest from U.S. bridge owners and researchers for variety of highway infrastructure applications. Some of these applications include using UHPC as a retrofit solution for structurally deficient members (Massicotte and BoucherProulx, 2010), as a structural overlay for deteriorating bridge decks (Brühwiler et al., 2015), and for new bridge structural elements such as precast girders and lighter weight bridge decks (Saleem et al., 2011). One application that is gaining significant attention from bridge owners is the use of UHPC as a closure-pour grout in prefabricated bridge construction. In recent years, there has been a significant push by both federal and state transportation agencies to expedite the delivery of new and replacement bridge construction projects. This has been appropriately termed accelerated bridge construction (ABC). Along with innovative funding and contracting methods, many ABC projects are heavily reliant on the use of prefabricated bridge elements (PBEs) to meet tight project schedules. The benefit of PBEs is that they can be fabricated offsite, and then rapidly assembled once delivered.

The performance of prefabricated bridge systems is highly dependent on the design and detailing of connections between elements. Typically, elements are joined using field-cast grout (or cast-in-place concrete) cast over interlaced reinforcing bars. The ideal grout for PBE connections is self-consolidating, has high early strength, good dimensional stability, good durability, and bonds well to precast concrete. Traditionally, these closure pours have been made using non-shrink cementitious grouts which provide some of the aforementioned properties but may lack others. As previously noted, UHPC is emerging as a viable substitute for these 
conventional cementitious connection grout materials because the fresh and hardened properties of UHPC-class materials align with the desired properties of PBE connection grouts.

As the interest in UHPC-class materials for PBE connections grows, interested bridge owners will look to better understand the properties of UHPC-class materials. To meet this growing need, the structural concrete research group at the FHWA Turner-Fairbank Highway Research Center is currently conducting a study on the performance of five different, commercial-available UHPC-class materials that may be suitable for PBE connections.

\section{Materials}

Five UHPC materials were selected for this study as shown in Table 1 . In all of them, preblended dry powders are mixed with water, chemical admixtures, and $2 \%$ of fibers (by volume), following the mixing procedures recommended by the manufacturers. Material U-B contains two types of fibers.

Table 1. UHPC materials used in the study

\begin{tabular}{|c|c|c|c|c|c|c|c|c|c|c|}
\hline \multirow{2}{*}{$\begin{array}{l}\text { Designation } \\
\text { Mix Design }\end{array}$} & \multicolumn{2}{|c|}{ U-A } & \multicolumn{2}{|c|}{ U-B } & \multicolumn{2}{|c|}{ U-C } & \multicolumn{2}{|c|}{ U-D } & \multicolumn{2}{|c|}{ U-E } \\
\hline & $\mathrm{lb} / \mathrm{yd}^{3}$ & $\left(\mathrm{~kg} / \mathrm{m}^{3}\right)$ & $\mathrm{lb} / \mathrm{yd}^{3}$ & $\left(\mathrm{~kg} / \mathrm{m}^{3}\right)$ & $\mathrm{lb} / \mathrm{yd}^{3}$ & $\left(\mathrm{~kg} / \mathrm{m}^{3}\right)$ & $\mathrm{lb} / \mathrm{yd}^{3}$ & $\left(\mathrm{~kg} / \mathrm{m}^{3}\right)$ & $\mathrm{lb} / \mathrm{yd}^{3}$ & $\left(\mathrm{~kg} / \mathrm{m}^{3}\right)$ \\
\hline Pre-blended dry powders & $3503^{\dagger}$ & $(2078)^{\dagger}$ & 3516 & (2086) & 3600 & (2136) & 3700 & (2195) & 3236 & $(1920)$ \\
\hline Water & 278 & $(165)$ & 354 & $(210)$ & 268 & (159) & 219 & $(130)$ & 379 & $(225)$ \\
\hline Chemical admixtures & 23 & (13.7) & 48 & $(28.7)$ & preb & ended $^{*}$ & $89^{\dagger \dagger}$ & $(53)^{\dagger \dagger}$ & 73 & (44) \\
\hline Steel fiber content & 277 & $(126)$ & $88 / 179$ & $(52 / 106)$ & 272 & (123.6) & 263 & $(156)$ & 156 & $(156)$ \\
\hline \multicolumn{11}{|l|}{$\underline{\text { Steel Fiber }}$} \\
\hline $\begin{array}{l}\text { Tensile strength, ksi } \\
\quad(\mathrm{MPa})\end{array}$ & & & \multicolumn{2}{|c|}{$\begin{array}{l}\geq 305(2100) / \\
\geq 305(2100)\end{array}$} & \multicolumn{2}{|c|}{348 (2400) } & \multicolumn{2}{|c|}{399 (3750) } & \multicolumn{2}{|c|}{399 (3750) } \\
\hline Length, in (mm) & \multicolumn{2}{|c|}{$1.18(30)^{\ddagger}$} & \multirow{2}{*}{\multicolumn{2}{|c|}{$\begin{array}{l}0.5(13) / 0.79(20) \\
0.012(0.3) / 0.012\end{array}$}} & \multicolumn{2}{|c|}{$0.5(13)$} & \multicolumn{2}{|c|}{$0.5(13)$} & \multicolumn{2}{|c|}{$0.5(13)$} \\
\hline Diameter, in (mm) & \multicolumn{2}{|c|}{$0.022(0.55)^{\ddagger}$} & & & \multicolumn{2}{|c|}{$0.012(0.3)$} & \multicolumn{2}{|c|}{$0.008(0.2)$} & \multicolumn{2}{|c|}{$0.008(0.2)$} \\
\hline \multirow{2}{*}{\multicolumn{11}{|c|}{$\begin{array}{l}{ }^{\dagger} \text { : Not pre-blended but come in as separate ingredients, which include fine silica sand, finely ground quartz flour, Portland cement, and } \\
\text { amorphous micro-silica } \\
{ }^{*} \text { : The chemical admixtures were dry powders and pre-blended with other powder ingredients }\end{array}$}} \\
\hline & & & & & & & & & & \\
\hline \multicolumn{11}{|c|}{$\begin{array}{l}{ }^{\dagger} \text { : It includes three chemicals, a modified phosphonate plasticizer, a modified polycarboxylate high-range water-reducing admixture, and } \\
\text { a non-chloride accelerator }\end{array}$} \\
\hline
\end{tabular}

\section{Testing Methods}

\subsection{Fresh Properties: Flowability and Setting Time}

Fresh flowability of the UHPC materials was assessed in accordance with the method described in ASTM C1437 (ASTM, 2015). The material is poured in a cone mold placed on top of a standard flow table. The mold is lifted and the flow is measured before and after applying 20 drops on the table for the determination of the static and dynamic flows, respectively. The flow is assessed by measuring the diameter along the four lines marked on the table, taking the average value. This measurement was taken immediately after mixing.

The setting time of the mixtures was measured according to ASTM C403 (ASTM, 2008). The test is based on measuring the pressure force needed to force a set of standard flat-headed needles to penetrate 1 inch $(25.4 \mathrm{~cm})$ into the material being tested. The material is placed in a 6- 
inch- (152-cm-) diameter by 6-inch- (152-cm-) height cylinder and stored in a controlled environmental room at $73.4^{\circ} \mathrm{F} \pm 1.8^{\circ} \mathrm{F}\left(23^{\circ} \mathrm{C} \pm 1{ }^{\circ} \mathrm{C}\right)$ and a relative humidity (RH) of $50 \pm 5 \%$. Readings are taken periodically after placing the material until a pressure of 4,000 psi (27.6 $\mathrm{MPa}$ ) is reached. This indicates the time of final set, whereas a pressure of $500 \mathrm{psi}$ (3.45 MPa) indicates the initial setting time.

\subsection{Dimensional Stability}

\subsubsection{Fresh Expansion/Contraction}

The early expansion and contraction movements were measured in terms of the height change as a function of time of a 3-inch- (76-mm-) diameter by 6-inch- (152-mm-) tall cylindrical specimen. This is done in accordance with a modified version of ASTM C827 (ASTM, 2010), previously published elsewhere (Di Bella and Graybeal, 2014). In this test, a non-contact laser is placed above the specimen and used to measure the vertical distance from the laser to the indicator ball placed on the top surface of the specimen. The measured vertical distance corresponds to the increase or decrease in height (expansion or contraction) of the material laterally confined in the cylindrical mold from the time of molding to when the mixture becomes hard (i.e., final set).

\subsubsection{Autogenous and Drying Deformations}

Autogenous (sealed) and drying deformations were assessed in three $3 \times 3 \times 11.25$ inch (76 x 76 x $286 \mathrm{~mm}$ ) prismatic specimens in accordance with ASTM C157 (ASTM, 2014). For autogenous measurements, the specimens were sealed with two layers of aluminum tape after removal from the molds at $24 \mathrm{~h}$. To guarantee isothermal conditions, all specimens were kept in an environmental room at $73.4^{\circ} \mathrm{F} \pm 1.8^{\circ} \mathrm{F}\left(23^{\circ} \mathrm{C} \pm 1{ }^{\circ} \mathrm{C}\right)$ and an $\mathrm{RH}$ of $50 \pm 5 \%$. Length change measurements, as well as mass measurements, were taken periodically starting at 1 day of specimens' age.

\subsection{Mechanical Properties}

\subsubsection{Compressive Strength}

The compressive strength of UHPC was evaluated using three 3-inch-diameter by 6-inch-tall (76-mm by 152-mm) cylindrical specimens tested in accordance with ASTM C39. However, the loading rate was increased from $35 \mathrm{psi} / \mathrm{sec}(0.24 \mathrm{MPa} / \mathrm{sec})$ to $150 \mathrm{psi} / \mathrm{sec}(1.0 \mathrm{MPa} / \mathrm{sec})$ based on previous research conducted by Graybeal (Graybeal, 2007). After casting, specimens were left undisturbed within their molds for curing in a laboratory environment of $73.4^{\circ} \mathrm{F} \pm 3.6^{\circ} \mathrm{F}\left(23^{\circ} \mathrm{C}\right.$ $\pm 2{ }^{\circ} \mathrm{C}$ ). Prior to testing, specimens were de-molded and the cylinders ends were prepared used a grinding machine. For a given age, a set of three cylinders were tested.

\subsubsection{Bond and Tensile Strength}

Bond and tensile strengths were measured using the ASTM C1583 test method, which is otherwise referred to as a direct tension "pull-off" test (see Figure 1) (ASTM, 2013). The test specimen consisted of a concrete base slab that measured 36 × 36 x 4 inches (914 x 914 x 102 $\mathrm{mm})$. The slab was cured for at least 28 days after casting at laboratory conditions of $73.4^{\circ} \mathrm{F} \pm$ $3.8^{\circ} \mathrm{F}\left(23^{\circ} \mathrm{C} \pm 2{ }^{\circ} \mathrm{C}\right)$ and an $\mathrm{RH}$ of $50 \pm 5 \%$. The concrete mixture design was specified to 
provide a slump of 6 inches and a compressive strength of 6000 psi. The surface of the substrate was prepared using an in-form retarder to achieve an exposed aggregate surface. This preparation method is easy to implement and provides sufficient roughness for an enhanced bond performance (De la Varga et al., 2016). Then, a 2-inch- (51-mm-) thick layer of the UHPC material was cast over the (exposed) top surface of the concrete panel so that an interface between the two materials is created. The UHPC was then cured for 7 and 14 days prior to execution of the pull-off bond tests. While for the pull-off bond tests the drilling penetrated approximately 1 inch $(51 \mathrm{~mm})$ below the interface as indicated in Section A-A of Figure 1, for the tensile tests, the drilling did not penetrate more than 1 inch $(51 \mathrm{~mm})$ from the top surface of the UHPC material (that is, drilling ceased well prior to the interface).
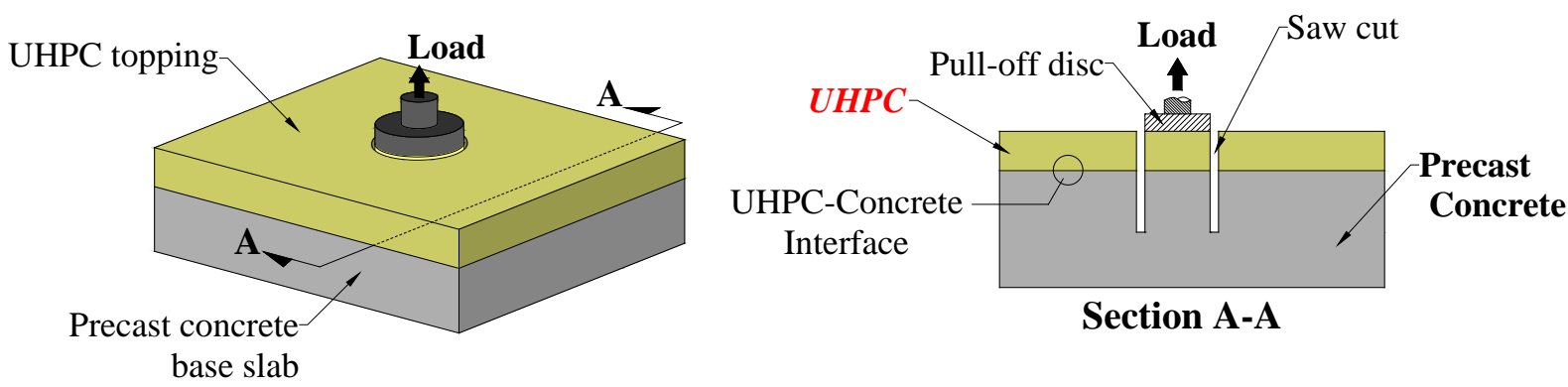

Figure 1. Illustration of the pull-off tests via ASTM C1583

\section{Results and Discussion}

\subsection{Fresh Properties: Flowability and Setting Time}

Table 2 shows the flowability and setting time values obtained for each of the UHPC materials. The results show similar values of dynamic flow. It should be mentioned though that the flowability can be adjusted by changing the water content, adjusting the chemical admixtures, controlling the plastic concrete temperature (such as using chilled water), adjusting the fiber content, or other techniques recommended by the manufacturers. Regarding the setting time, this parameter is directly related to the kinetics of the chemical reactions taking place in the system, which depend on both the premix formulation and the chemical admixtures used. The results show variability in this regard. Materials U-A and U-E exhibited longer setting times, making difficult the proper and accurate measurement of this material property.

Table 2. Flowability and setting time of UHPC materials

\begin{tabular}{|c|c|c|c|c|c|c|}
\hline \multicolumn{2}{|c|}{ Material Property } & U-A & U-B & U-C & U-D & U-E \\
\hline \multirow{2}{*}{ Flowability (in) } & Static & 5.75 & $>10.00$ & 4.00 & 7.50 & 7.13 \\
\cline { 2 - 7 } & Dynamic & 8.63 & $>10.00$ & 7.63 & 9.00 & 8.75 \\
\hline \multirow{2}{*}{ Setting Time (h) } & Initial & n.d & 8.0 & 4.3 & 5.3 & $>9.0$ \\
\cline { 2 - 7 } & Final & $<15.0$ & 10.1 & 8.0 & 7.0 & $<24.0$ \\
\hline
\end{tabular}

1 inch $=25.4 \mathrm{~mm}$

n.d. = not determined 


\subsection{Dimensional Stability}

\subsubsection{Fresh Expansion/Contraction}

Fresh volume contractions are normally detected in the form of material settlement. From a practical perspective, settlements of field-cast grouts can be remediated by over-pouring the PBE connections. If, after the closure pour, the surface is uneven, grinding can be employed to remove the material excess to achieve a flush surface. However, settlements are also indicative of the dimensional instability of the material. Figure 2 shows the dimensional stability in terms of height change (i.e., expansion and contraction) of the UHPC materials used in this study. As observed, all the UHPC materials undergo a height reduction of less than $1 \%$, except for U-E which exceeds this value. In most cases, a fast decrease in height is observed over the first 2-3 hours. The measured height reduction cannot be exclusively correlated to settlement or shrinkage since the height change measurement would include a variety of simultaneous effects such as chemical and autogenous shrinkage, surface settlement, and plastic shrinkage (due to drying of the specimen from the top surface).

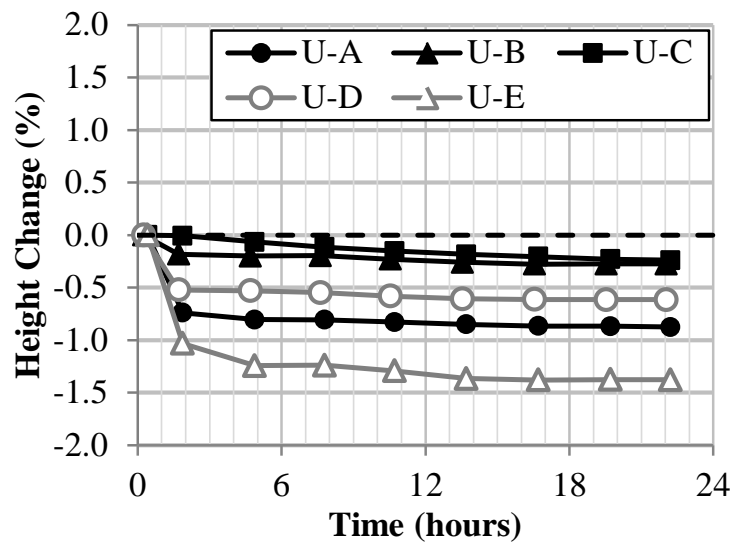

Figure 2. Fresh change in height of UHPC materials

\subsubsection{Autogenous and Drying Deformations}

Figure 3 shows the autogenous (sealed) and drying deformations of the UHPC materials from 1 day to 3 months of specimens age. As observed, all UHPC materials undergo shrinkage throughout the duration of the test. In some cases the amount of autogenous shrinkage is high, reaching values above $400 \mu \varepsilon$ after only 7 days of hydration. As for the drying deformations, it is interesting to note that the shrinkage values are not particularly higher than those observed in sealed conditions. Typically drying shrinkage is about an order of magnitude larger than sealed shrinkage in conventional concretes. Overall, these dimensional stability test results demonstrate that the shrinkage of UHPC is commonly within the range associated with well-designed conventional concretes, however, the values can be somewhat higher for some products or mix designs. 


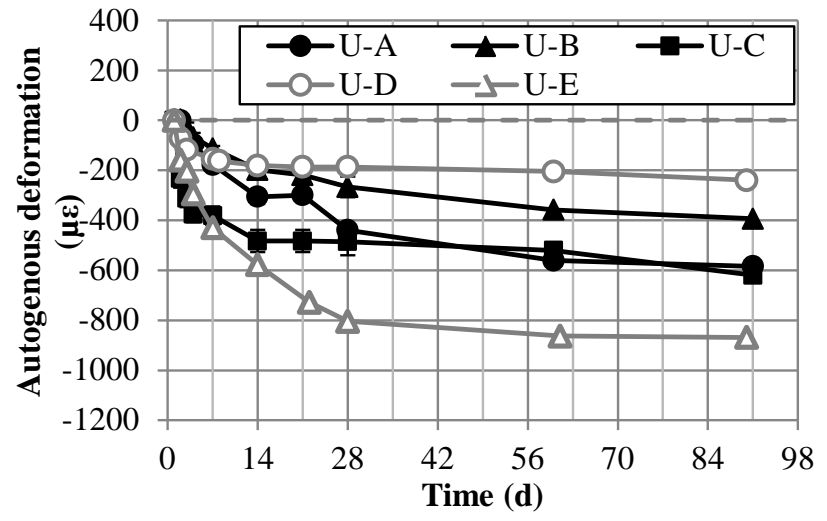

(a)

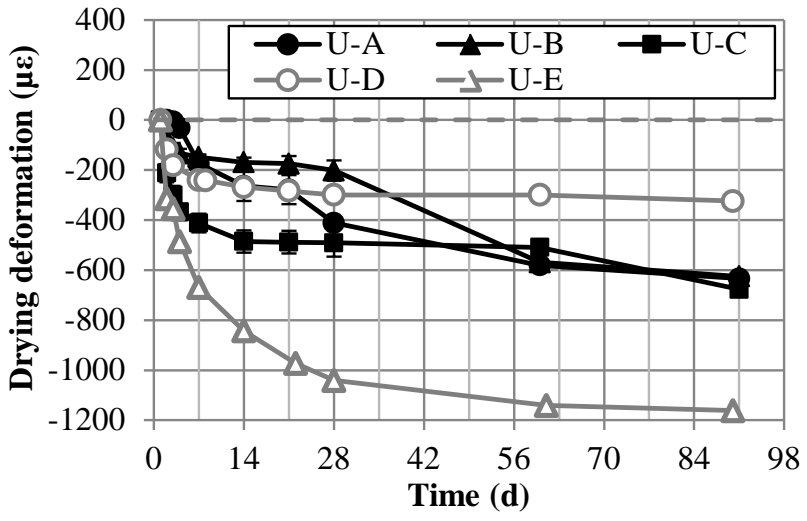

(b)

Figure 3. (a) Autogenous and (b) drying deformations of UHPC materials. (Error bars represent \pm one standard deviation from the average of three samples)

It must also be recognized that dimensional instability during the early age mechanical property development can cause distress in the material and can hinder the long-term performance of the constructed system. UHPCs commonly exhibit proportionally more autogenous shrinkage than conventional concretes, particularly at early ages. The ASTM C1698 test method can capture these early age dimensional stability behaviors; however, the test can be difficult to complete for heavily fiber reinforced materials and thus the cementitious matrix without the fiber reinforcement may need to be assessed (De la Varga and Graybeal, 2014).

\subsection{Mechanical Properties}

\subsubsection{Compressive Strength}

Results from compression tests at different ages are shown in Figure 4. Each data point represents the average of three samples, and a set of error bars are shown to represent plus or minus one standard deviation. Material U-D exhibited the most rapid strength gain, which is not unexpected given that this material employs an accelerator. Material U-E, exhibited the slowest rate of strength gain over time. The other three UHPC-class materials exhibited strength gain rates somewhere between the two aforementioned products.

In ABC projects, curing of closure-pour grouts can be a critical path operation, thus is it critical to understand when construction or traffic loads can be allowed in a bridge structure. The FHWA publication, Design and Construction of Field-Cast UHPC Connections (Graybeal, 2014), recommends that UHPCs with $2 \%$ fiber by volume should reach a compressive strength of at least $14 \mathrm{ksi}(97 \mathrm{MPa})$ prior to being subjected to structural loads. As can be seen in Figure 4(a), this strength is gained by each of the UHPC-class materials prior to 5 days of age. To further examine the strength gain properties of these materials at early ages, a simple logarithmic trend line was fit to the data collected between ages of 1-day and 28-days. Figure 4(b) presents each strength-gain trend line up to an age of 14 days; each trend line had an $R^{2}$ value greater than 0.95. It can be observed that the recommended minimum strength of $14 \mathrm{ksi}$ (97 MPa) is achieved between 1.0 and 4.5 days of age for these different UHPC-class materials when cured in a standard laboratory environment. 


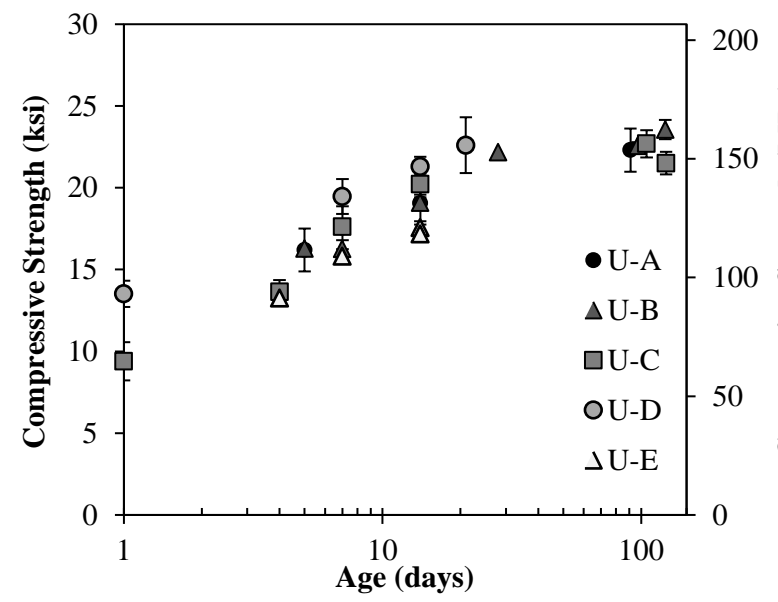

(a)

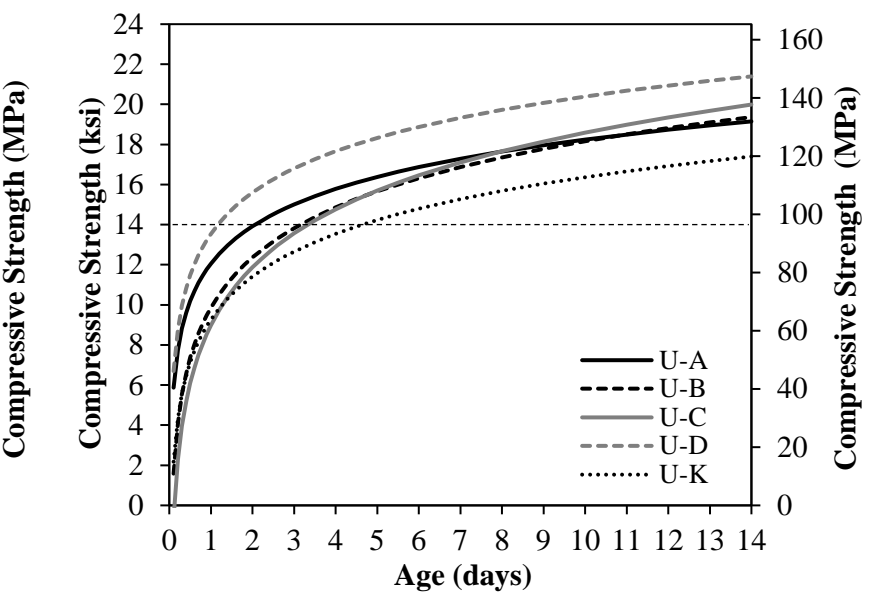

(b)

Figure 4. (a) Compressive strength vs. age, (b) Early-age strength-gain using a best-fit curve

\subsubsection{Bond and Tensile Strength}

Direct tensile pull-off tests were performed to assess the bond strength of UHPC-concrete slabs as well as the tensile strength of the UHPC materials. Figure 5 shows the results obtained. The results are presented as "7-day" and "14-day" bond strength which refers to the age of the UHPC material when the bond test was performed. As observed in the plot, the bond strength of these materials varies from each other. Given that bond is affected by several material parameters (e.g., rheology, fineness, tensile strength, etc.), some differences are expected. As observed, the bond strength of these materials does not seem to increase over time. In fact it decreases in some cases (U-C, U-E). The large measured shrinkage in these two materials at 7 and 14 days might have something to do with the reduction of the bond strength at these ages. In regards to the tensile strength, all mixes range between 750 psi (5.2 MPa) and $1000 \mathrm{psi}(6.9 \mathrm{MPa})$ at the ages tested. These values are considered to be the elastic tensile strength (i.e., maximum stresses obtained before the occurrence of the first crack). 


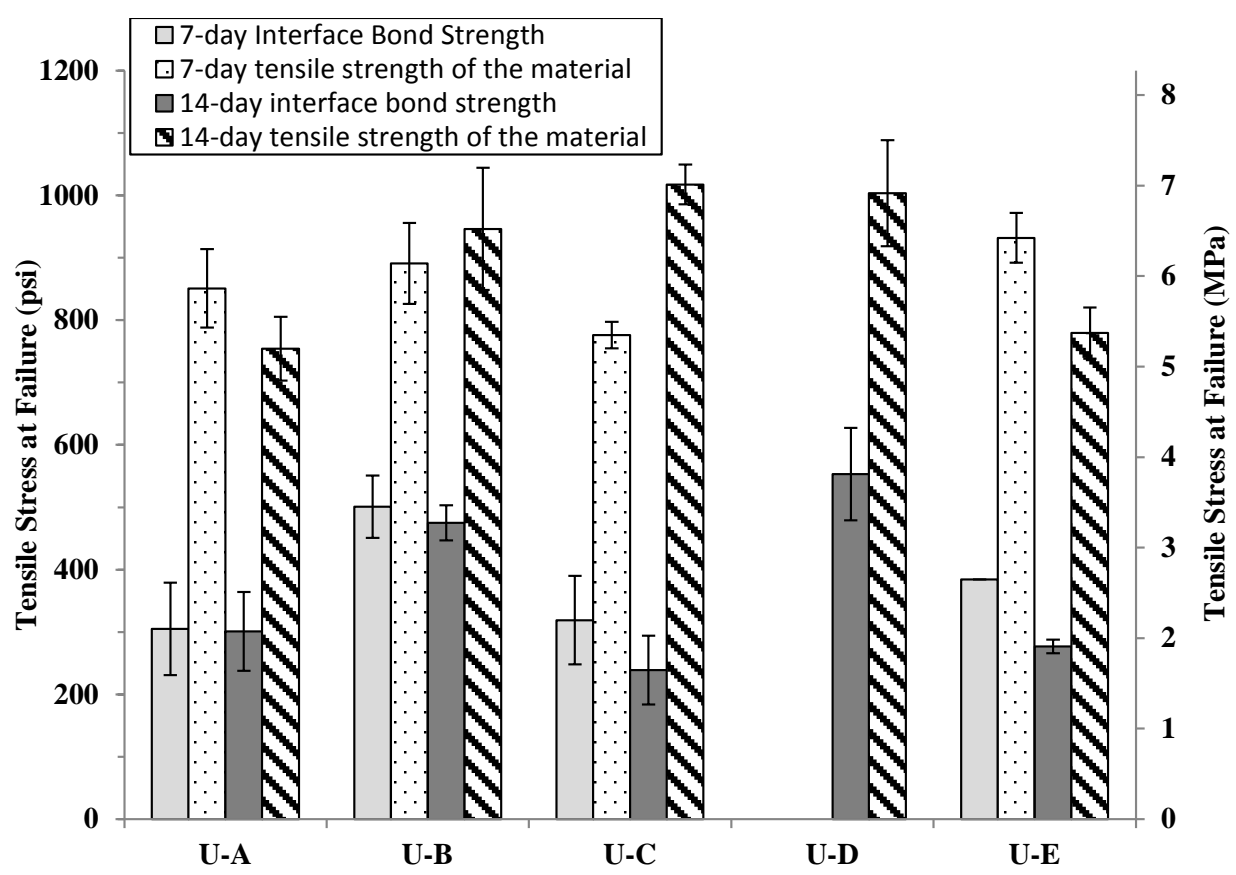

Figure 5. Bond and tensile strength of UHPC materials (7-d strengths were not measured for the U-D material). (Error bars represent \pm one standard deviation from the average of five samples)

\section{Conclusions}

UHPC-type materials have shown growing interest within the infrastructure community. Special focus is given to the use of these materials as PBE closure pours in precast construction. A series of key material properties have been evaluated and are presented in this paper on a selection of five commercially-available UHPC products. The following conclusions can be drawn:

- In regards to the fresh properties evaluated (flowability and setting time), the materials show different static flow but similar values of dynamic flow. However, the materials can be tailored to offer similar flows, if needed. On the other hand, setting times will directly depend on the premix formulation and chemical admixtures used in each of the products. As such, considerable differences are observed in terms of setting time.

- Four of the five UHPC materials tested exhibit less than $1 \%$ of fresh contraction (commonly seen as "fresh settlement", although other parameters such as plastic and autogenous shrinkage are also considered in this measurement). In terms of field applications, this settlement can be mitigated by over-pouring. The tested materials all display shrinkage, primarily autogenous. The total shrinkage values vary by material, and can be considered to fall within the range of values commonly observed for conventional concretes and grouts.

- While the materials tested exhibited similar mechanical properties in terms of compressive and tensile strength, the bond performance differed from each other. It is important to mention that the bond of these materials to a concrete element is highly influenced by the properties of the fresh material being bonded to the concrete substrate (i.e., rheology, fineness, tensile strength, etc.). Therefore, further studies should be executed to better understand the different bond performances obtained. 


\section{Acknowledgments}

The authors would like to thank the TFHRC Concrete and Structures laboratories staff for their technical assistance. The research presented in this paper was funded by the U.S. Federal Highway Administration. Fresh property and dimensional stability testing was performed under contract DTFH61-13-D-00007, and the compressive strength and bond tests were performed under contract DTFH61-10-D-00017. This support is gratefully acknowledged. The publication of this report does not necessarily indicate approval or endorsement of the findings, opinions, conclusions, or recommendations either inferred or specifically expressed herein by the Federal Highway Administration or the United States Government.

\section{References}

Brühwiler, E., et al., "Strengthening the Chillon viaducts deck slabs with reinforced UHPFRC." IABSE Conference Geneva 2015 "Structural Engineering: Providing Solutions to Global Challenges". No. EPFL-CONF-212773. IABSE, 2015.

De la Varga I., Graybeal B.A., "Dimensional Stability of Grout-Type Materials Used as Connections between Prefabricated Concrete Elements", Journal of Materials in Civil Engineering, Vol. 27, No. 9, November 2014.

De la Varga, I., Haber, Z.B., and Graybeal, B.A., "Performance of Grouted Connection for Prefabricated Bridge Elements Part II: Material-Level Investigation on Shrinkage and Bond,” Proceedings of the 2016 PCI National Bridge Conference, Nashville, TN, USA, 2016, 11 pp.

Di Bella C, Graybeal B.A., "Volume stability and cracking potential of pre-bagged, cementbased non-shrink grouts for field-cast connections", Transportation Research Record: Journal of the Transportation Research Board. Vol. 2441, December 2014, pp. 6-12.

Graybeal B.A., "Compressive behavior of ultra-high-performance fiber-reinforced concrete”, ACI Materials Journal, Vol. 104, No. 2, March 2007, pp. 146.

Graybeal, B.A., "Design and Construction of Field-Cast UHPC Connections”, FHWA, U.S. Department of Transportation, Report No. FHWA-HRT-14-084. 2014.

Massicotte, B., Boucher-Proulx, G., "Seismic retrofitting of bridge piers with UHPFRC jackets." Designing and Building with UHPFRC, February 2010, pp. 531-540.

Saleem, M.A., et al., "Ultra-High Performance Concrete Bridge Deck Reinforced with HighStrength Steel,” ACI Structural Journal, Vol. 108, No. 5, 2011, pp. 601-609.

Standard Test Method for Time of Setting of Concrete Mixtures by Penetration Resistance, ASTM C403, ASTM International, Volume 04.02, West Conshohocken, PA, 2008.

Standard Test Method for Change in Height at Early Ages of Cylindrical Specimens of Cementitious Mixtures, ASTM C827, ASTM International, Volume 04.02, West Conshohocken, PA, 2010. 
Standard Test Method for Tensile Strength of Concrete Surfaces and the Bond Strength or Tensile Strength of Concrete Repair and Overlay Materials by Direct Tension (Pull-off Method), ASTM C1583, ASTM International, Volume 04.02, West Conshohocken, PA, 2013.

Standard Test Method for Length Change of Hardened Hydraulic-Cement Mortar and Concrete, ASTM C157, ASTM International, Volume 04.02, West Conshohocken, PA, 2014.

Standard Test Method for Flow of Hydraulic Cement Mortar, ASTM C1437, ASTM International, Volume 04.01, West Conshohocken, PA, 2015. 